This item was submitted to Loughborough's Research Repository by the author.

Items in Figshare are protected by copyright, with all rights reserved, unless otherwise indicated.

\title{
Additive manufacturing of intricate and inherently photocatalytic flow reactor components
}

PLEASE CITE THE PUBLISHED VERSION

https://doi.org/10.1016/j.addma.2020.101828

PUBLISHER

Elsevier

VERSION

AM (Accepted Manuscript)

\section{PUBLISHER STATEMENT}

This paper was accepted for publication in the journal Additive Manufacturing and the definitive published version is available at https://doi.org/10.1016/j.addma.2020.101828.

LICENCE

CC BY-NC-ND 4.0

\section{REPOSITORY RECORD}

Xuan, Jin, Adilet Zhakeyev, Mary C Jones, Christopher G Thomson, John M Tobin, Huizhi Wang, and Filipe Vilela. 2020. "Additive Manufacturing of Intricate and Inherently Photocatalytic Flow Reactor Components". Loughborough University. https://hdl.handle.net/2134/13604336.v1. 


\title{
Additive manufacturing of intricate and inherently
} photocatalytic flow reactor components

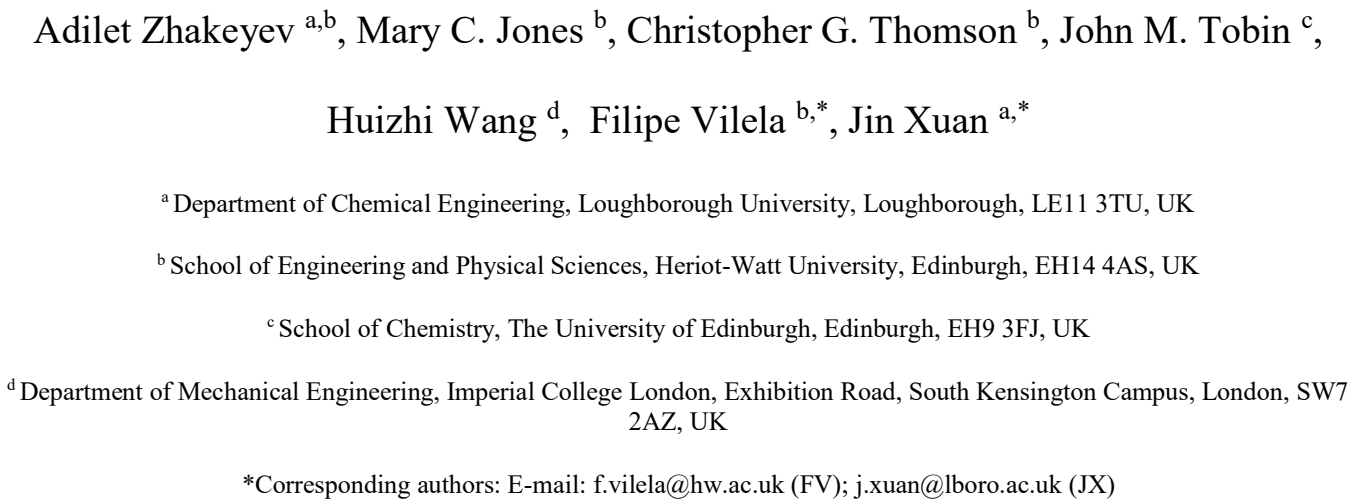

\begin{abstract}
A 2,1,3-benzothiadiazole-based photosensitiser has been successfully incorporated into a commercially available $3 \mathrm{D}$ printing resin and utilised to fabricate inherently photocatalytic flow reactor components. The freedom of design provided by additive manufacturing enabled the production of photoactive monolith structures with intricate architectures, imparting functionality for heterogeneous photocatalysis and interesting manipulation of fluid dynamics within a fixed bed reactor column. The resultant monoliths were applied and validated in the photosensitisation of singlet oxygen in aqueous media, under continuous flow conditions and visible light irradiation $(420 \mathrm{~nm})$. The photo-generated singlet oxygen cleanly converted furoic acid to the $\gamma$-lactone, 5 -hydroxy-5H-furan-2-one, with a peak space-time yield of $2.34 \mathrm{mmol} \mathrm{m}^{-2} \mathrm{~h}^{-1}$ achieved using the Voronoi monolith.
\end{abstract}

Keywords: 3D printing, flow technology, metal-free organic photosensitiser, singlet oxygen

\section{Introduction}

Within the last decade, additive manufacturing (AM) has emerged as an enabling technology for the fabrication of complex 3D components. With 3D printer technology becoming increasingly affordable and 
1 accessible, it seems inevitable that this technology will continue to be ever more present as a standard 2 accessory of research institutions. AM has already found much utility within chemical science, especially

3 for biomaterials research where AM has enabled the fabrication of biocompatible scaffolds that permit cell 4 growth in three dimensions to imitate organs [1].

5

6 a variety of applications, including heterogeneous catalysis. The freedom of design offered by AM enables

7 the production of complex material architectures with high surface area and static mixing capabilities; ideal support materials for heterogeneous catalysts [2]. Monolithic structures with various metal and metal oxide catalysts have been fabricated via fused deposition modelling (FDM) for synthetic applications, such as a cylindrical lattice printed from $\mathrm{Al}_{2} \mathrm{O}_{3}$ ink which acted as a heterogeneous Lewis acid catalyst in the synthesis of dihydropyridines and dihydropyrimidinones [3]. Cronin and co-workers have also prepared reactionware via FDM, which incorporated montmorillonite K10 Lewis acidic clay in one reaction chamber and palladium on charcoal $(\mathrm{Pd} / \mathrm{C} 10 \%)$ hydrogenation catalyst in a separate chamber, both of which were printed from specially prepared 'ink' materials [4].

FDM has some limitations for the fabrication of flow reactor devices; the nature of printing layer-to-layer creates anisotropy in the material, as well as voids between the individual layers. This affects the mechanical properties of the printed material and, more importantly for flow reactors, can affect the 'water tightness' as solution can percolate through the voids and present leaks [1,5]. Stereolithography (SL) is another form of AM which overcomes these obstacles. SL 3D printers' function through vatphotopolymerization of a liquid resin. The individual layers are covalently crosslinked, providing materials that are isotropic in all three dimensions, with no macroscopic grain structure or voids [1,5]. As SL 3D printers use liquid resins to form materials, catalysts with polymerizable functional groups can be easily incorporated into the resin, which results in the direct fabrication of functional materials. 


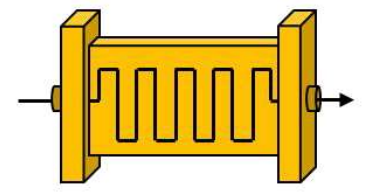

Photocatalyst in external surfaces block light from active sites in flow channels (2) Simple $2 \mathrm{D}$ design; could be
manufactured conventionally

1

2
3

4

5 Recently we present the first example of this methodology for the production of inherently photocatalytic

Figure 1: Comparison of disadvantages of A) previously reported SL manufacture of flow reactors and B) advantages of the manufactured functional monoliths presented in this work.

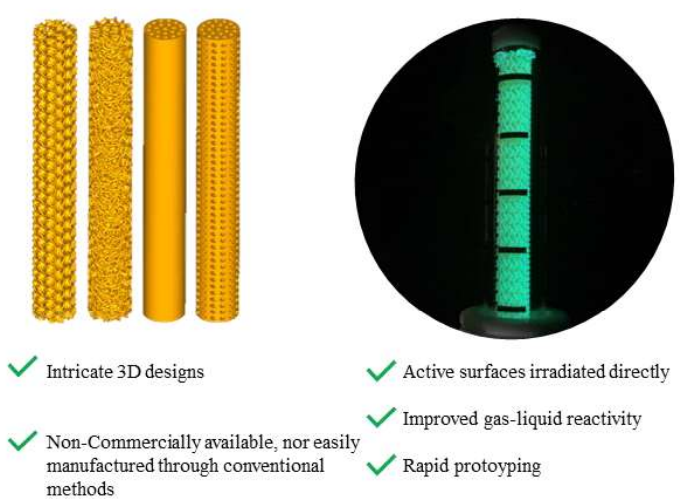

$$
\text { methods }
$$

advantage of the freedom of design offered by AM. Herein, we address those issues and have utilised AM's

freedom of design to fabricate intricate structures with potential for static mixing functionality. Four unique monolith structures have been fabricated and compared for efficiency, as well as analysing their effect on mixing performance through residence time distribution (RTD) studies (Figure 1B). The materials were then successfully applied as singlet oxygen $\left({ }^{1} \mathrm{O}_{2}\right)$ generators for the conversion of 2 -furoic acid (1, Scheme 2) to the $\gamma$-lactone, 5-hydroxy-5H-furan-2-one (2, Scheme 2$)$, in continuous flow.

\section{Material and methods}

\subsection{Design and fabrication of monoliths}

Following our previous 'proof of principle' study on the SLA fabrication of a photoactive microfluidic device, we identified some obstacles that we wished to address in this report [6]. Primarily, the irradiation of the 3D printed surface in contact with the reaction solution was suboptimal in the microfluid device, as the external surfaces of the reactor also contained photocatalyst which attenuated a significant amount of the incident irradiation, limiting the efficiency of the device. To overcome this, we have designed monolithic structures that are compatible with a fixed bed reactor, such that the surfaces in contact with the flowing reagents are directly exposed to the irradiation. We also wished to demonstrate and take full 
1 advantage of the freedom of design offered by 3D printing. Hence, four cylindrical monolith designs were

2 produced with increasingly intricate designs. D1 has a simple two-dimensional channel structure, parallel

3 and perpendicular to the long axis of the monolith. D2 is identical to D1, except the perpendicular channels are removed, forming a typical honeycomb type monolith design. The Voronoi and Gyroid designs are more complex, generated from a pseudo-random lattice and periodic lattice, respectively (Figure 2). Details of the designs and their generation can be found in the ESI (Section S4).

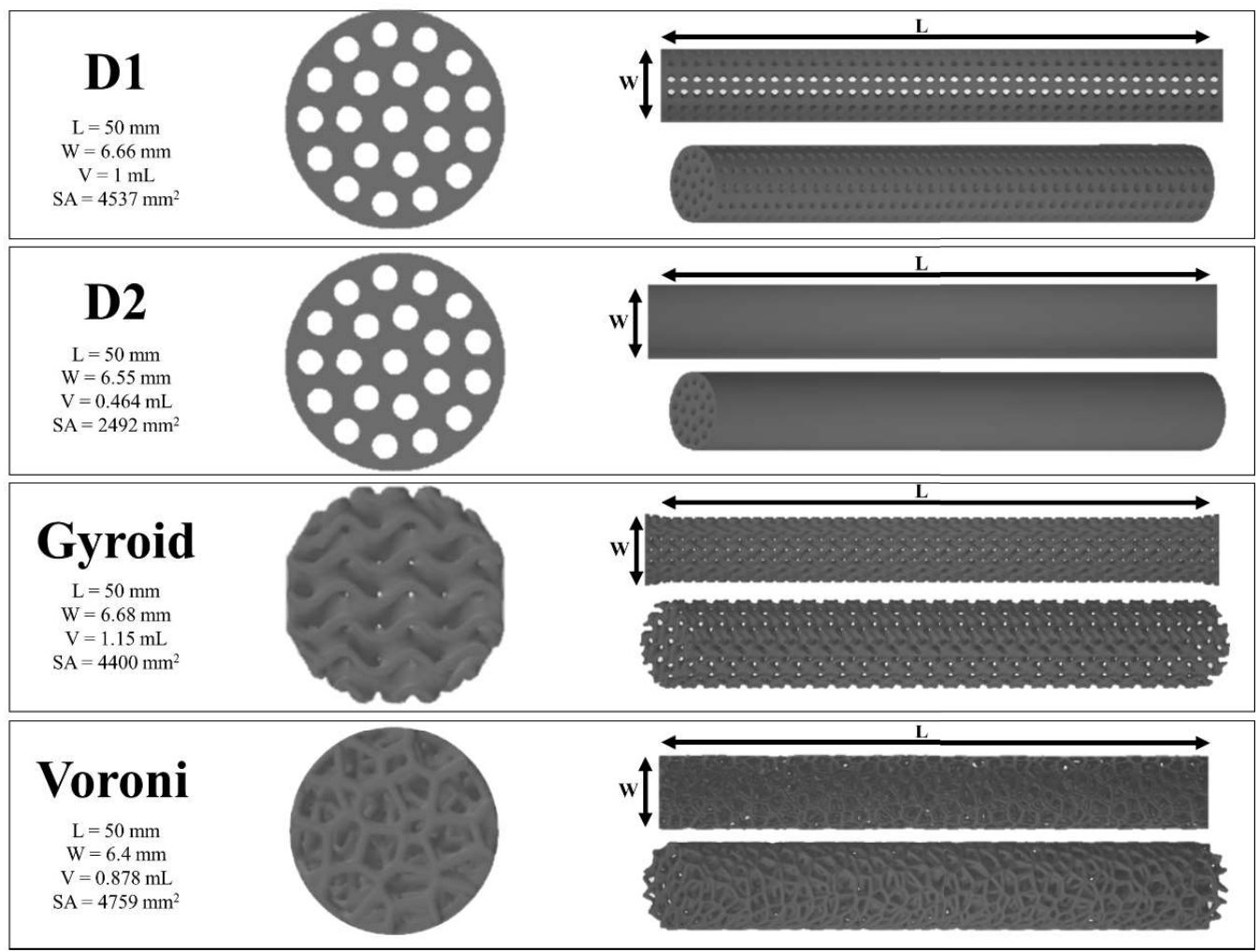

Figure 2: Computer-aided design (CAD) diagrams of the 4 different monolith designs with key geometric parameters $(\mathrm{L}=$ length, $\mathrm{W}=$ width, $\mathrm{V}=$ internal volume, $\mathrm{SA}=$ surface area).

\subsection{Optimisation of printing parameters for varied photocatalyst loadings}

12 The commercial resin used was Formlabs Clear Resin (FLGPCL05, Formlabs Inc., Somerville, MA, USA),

13 which is composed of a urethane dimethacrylate (55-75\%), methacrylate monomer(s) (15-25\%) and photoinitiator $(<0.9 \%)$ (Scheme 1). We chose to use 4,7-di(4-vinyl)phenylbenzo-2,1,3-thiadiazole (StBTZ, Scheme 1) as a photocatalyst monomer, as the vinyl groups are compatible with the acrylates resin during the photopolymerization process (Scheme 1). Details of the St-BTZ monomer synthesis and characterisation can be found in the ESI (Section S2). 


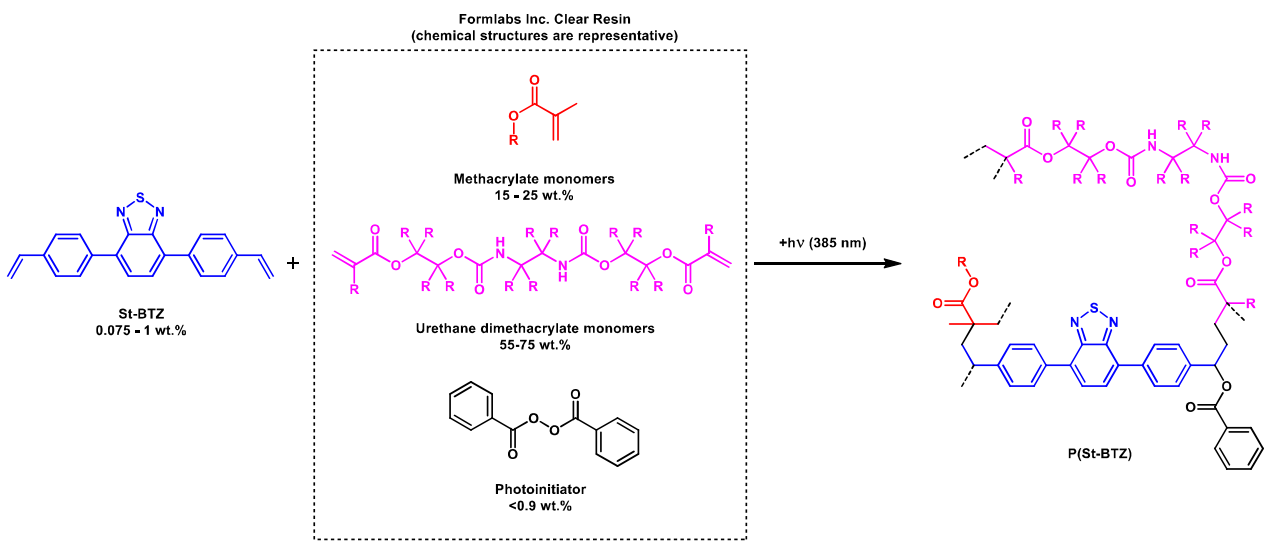

Scheme 1. Structure of St-BTZ and representative structures of methacrylate, urethane dimethacrylate and photoinitiator molecules which are the major components of the commercial resin. The exact structures are a trade secret and hence the identity of the photoinitiator, R-groups and chain lengths are unknown. A representative structure of the printed polymer material P(St-BTZ) is also given. Dashed bonds indicate a continuation of the polymer chain structure with any of the three monomer units, or a terminal capped with photoinitiator, in proportions respective of the resin composition.

3D printed prototypes were produced using a digital light processing (DLP) printer (PICO 2HD 27UV,

9 Asiga). The LED system of the DLP printer irradiates at $385 \mathrm{~nm}$, which the St-BTZ monomer also absorbs

10 (vide infra). This seems intuitively problematic; however, this can reduce over-irradiation and improve

11 printing resolution. To account for this, we first assessed the effect of the photocatalyst additive on the polymerisation kinetics via double bond conversion (DBC) rates. Real-time FTIR spectroscopy was used to monitor the $\mathrm{C}=\mathrm{C}$ stretching frequency of the vinyl and acrylate monomers at around $1620-1650 \mathrm{~cm}^{-1}$ as a function of time, while the sample was irradiated at $365 \mathrm{~nm}$. The change in absorption intensity can be used to calculate DBC following Equation 1.

$$
\mathrm{DBC}=\left[\frac{\mathrm{A}_{0}-\mathrm{A}_{\mathrm{t}}}{\mathrm{A}_{\mathrm{t}}}\right] \times 100
$$

17 Where the DBC is proportional to the initial absorption intensity before irradiation $\left(A_{0}\right)$ and the absorption intensity after a given irradiation time $\left(A_{t}\right)$. An example of the depleting signal intensity over time during irradiation is given in Figure 3A for the native resin with no St-BTZ additive. The effect of increasing StBTZ concentration on the polymerisation kinetics is shown in Figure 3B. Individual absorption traces for each of the concentrations can be found in the ESI (Section S3). 

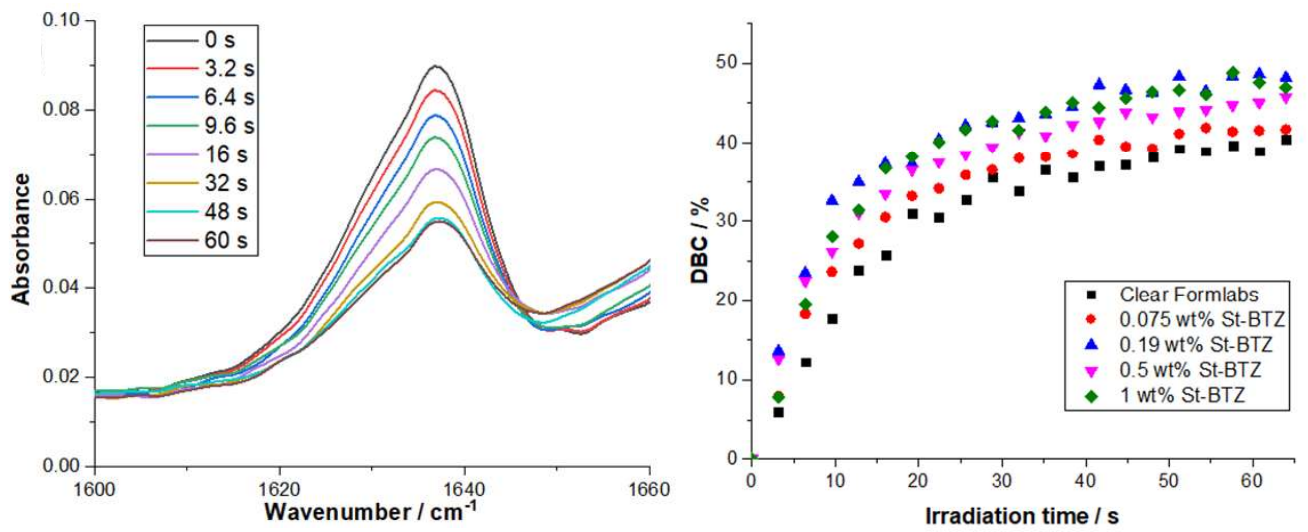

3

4

5

Figure 3: A) Real-time FTIR spectra of Formlabs Clear resin with 0 wt.\% St-BTZ. B) DBC (\%) vs. time trace for various St-BTZ wt. $\%$ loadings.

Addition of St-BTZ caused an increase in both the rate of polymerisation and the overall DBC value obtained. The trend between rate, DBC and St-BTZ wt.\% was relatively linear, except for 0.19 wt.\% StBTZ which had the fastest kinetics and highest overall DBC. We attribute this to be due to a balance between light attenuation and photosensitised acceleration of the photo-polymerisation (See ESI, Section S3) $[7,8]$.

\section{Results}

\subsection{Photophysical characterization}

St-BTZ displays a broad absorption profile in the range of 350-450 nm, with a maximum absorption intensity $\left(\lambda_{\max }\right)$ at approximately $380 \mathrm{~nm}$ (Figure 4A) [9]. This is almost perfectly aligned with the $385 \mathrm{~nm}$ light source of the DLP printer used for device fabrication. Adding St-BTZ to the resin resulted in an increase in absorption around the $350-450 \mathrm{~nm}$ region (Figure $4 \mathrm{~A}$ ). The peaks of the native resins are still visible up to 0.19 wt. $\%$. At 1 wt. $\%$, the light attenuation of the sample becomes too great and the definition of the profile is lost. Thin films of the 3D printed material were fabricated and analysed by solid-state UV-

9 Vis. spectroscopy for comparison. The solid samples showed an increasing absorption intensity around the 350-500 nm region with increasing St-BTZ concentration, as shown in Figure 4B. 

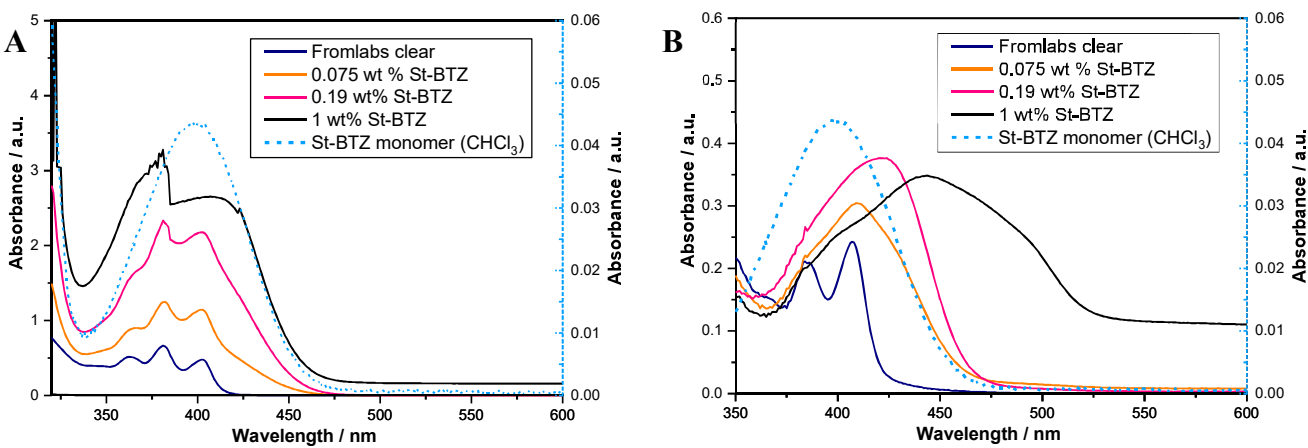

Figure 4: UV/vis absorption spectra of (A) Formlabs Clear resin with different St-BTZ concentrations (diluted in IPA) and (B) Solid-state UV-Vis. absorption spectra of 3D printed films with various St-BTZ concentration. The solution-state absorption spectrum of the St-BTZ monomer $\left(\mathrm{CHCl}_{3}\right)$ is shown as a dashed, light-blue line in both graphs for reference, with the $\mathrm{Y}$-axis shown on the right.

The $\lambda_{\max }$ undergoes a bathochromic shift with increasing St-BTZ concentration, comparable to the maximum absorbance wavelength $(420 \mathrm{~nm})$ reported by Tobin et al. for poly(styrene-co-DVB-co-(StBTZ)) [9]. The spectral profile of the 1 wt.\% St-BTZ film deviates from the other samples, showing a far greater bathochromic shift in absorption maximum to $440 \mathrm{~nm}$ and the emergence of an absorption from 500-600 nm. We found that higher St-BTZ content exceeded the solubility limit, leading to aggregation of the photocatalyst monomer. These macroscopic aggregates were visible in the printed films and altered the absorption profile through light scattering. Following these results, 0.19 wt.\% of St-BTZ was concluded as the optimal loading for providing the highest concentration of photosensitiser whilst maintaining a homogeneous resin mixture.

\subsection{Monolith fabrication and RTD analysis}

We proceeded to optimise the curing parameters for the photocatalyst-doped resin within the DLP printer, the results of which are tabulated in the ESI (Table S3). To confirm our results from the RT-FTIR kinetic analysis described in section 2.2, we printed prototype structures with each of the resins and found that the higher wt.\% loadings required significantly higher exposure times (c.f. 0 wt.\% optimised exposure time = 0.68 seconds, vs. 1 wt.\% optimised exposure time $=9$ seconds). After printing and washing in isopropanol, the monoliths were post-cured for one hour via Asiga Flash UV post-curing chamber (type DR-301C, 36 W, $365 \mathrm{~nm}$, Asiga). This shows that despite the enhanced kinetics of the polymerisation in the presence of photocatalyst, the subsequent light attenuation of the photocatalyst at greater curing depths did require a greater energy dose for successful printing, consistent with our previous report using an SLA printer [6].

We then fabricated the designs described in the first section using our established optimal loading of 0.19 wt.\% St-BTZ. Images of the cured monolith structures can be seen in Figure 5A. The printed monoliths 
1 pleasingly displayed the yellow colour of the St-BTZ monomer and showed no obvious defects or

2 inhomogeneity. The fluorescence of the material was observed qualitatively by irradiating with a UV lamp,

3 which also showed a uniform emission throughout the fabricated monoliths (Figure 5B). The finer details

4 of the prints were observed under a microscope with a calibrated scale (Figure 5C \& 5D), revealing the

5 channel void spaces of the D2 and Voroni monoliths were within $20 \%$ error of the intended designs

6 following the post-curing process (c.f. $874 \mu \mathrm{m}$ vs. $750 \mu \mathrm{m}$ ).

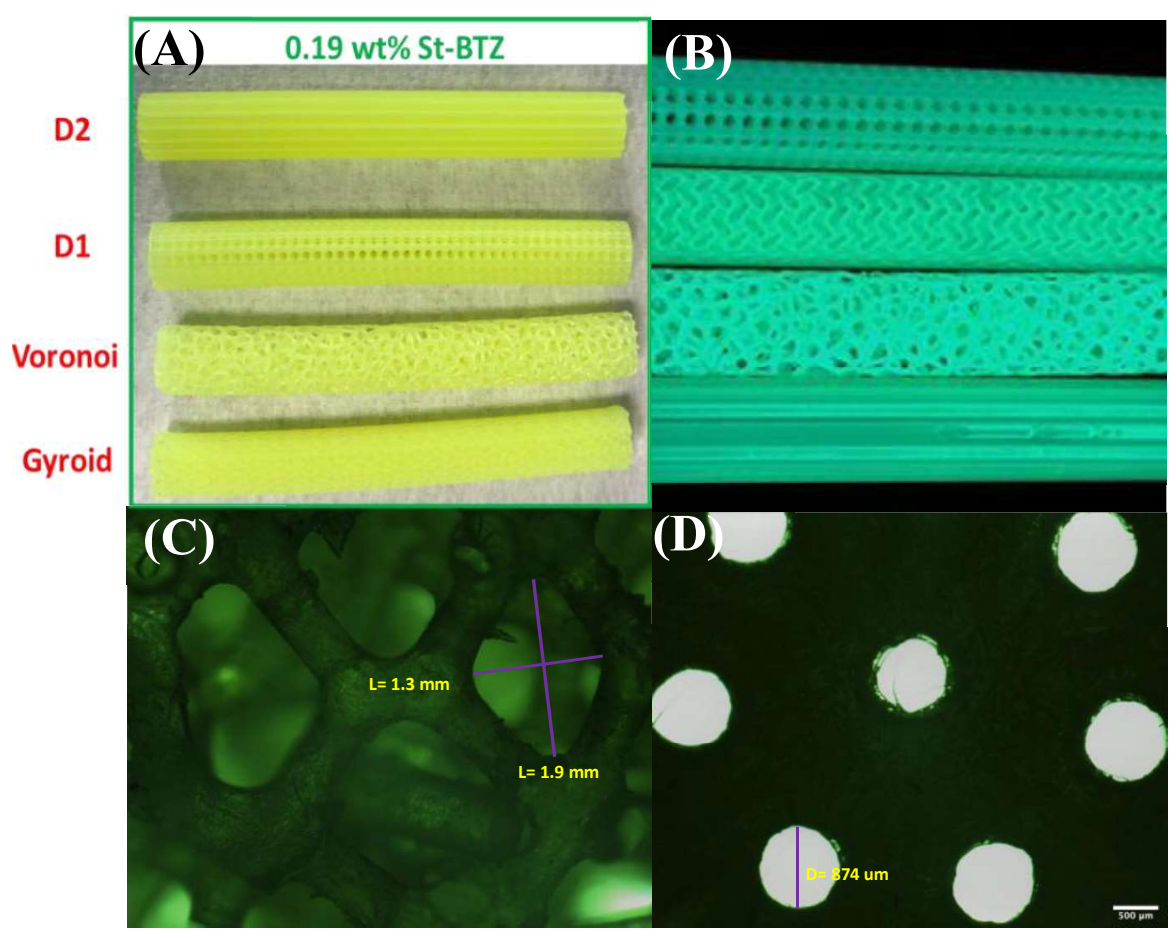

Figure 5: (A) 3D printed and cured photo-active monoliths with $0.19 \mathrm{wt} \% \mathrm{St}-\mathbf{B T Z}$ concentration. (B) Image of the monoliths under long-wave UV irradiation, showing the blue glow of the incorporated St-BTZ monomers (from top to bottom: D1, Gyroid, Voronoi, D2). (C) Microscope image of the Voroni monolith with length (L) of a diamond shaped void given for reference. (D) Microscope image of a cross section of the $\mathbf{D} 2$ monolith with channel diameter (D) given for reference.

The qualitative analysis of RTD can be used to detect deviation from ideal plug flow and mixed flow behaviours, which can be caused by stagnant regions, channelling, and recycling of fluid. We proceeded to test the monolithic structures effect on the RTD for a single-phase solution flow stream and biphasic solution-gas flow stream at varying flow rates. This study was performed using an optical tracer (methyl orange) in the solution phase and monitoring the absorption intensity of the outflow stream. A detailed discussion of the RTD experimental procedure and parameter derivations can be found in the ESI (Section S6), and the RTD profiles obtained are displayed in Figure $6 \&$ 7. RTD is frequently described by the mean 
1 residence time $(\tau)$, variance $\left(\sigma^{2}\right)$ and reduced variance $\left(\sigma_{\theta}^{2}\right)$, which were obtained and are displayed in the

a)

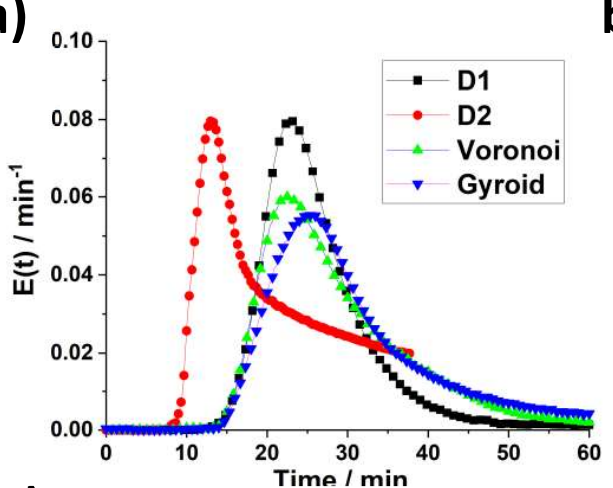

c)

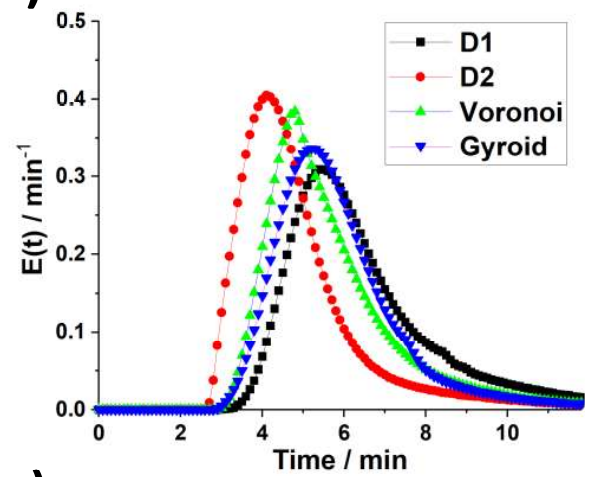

e)

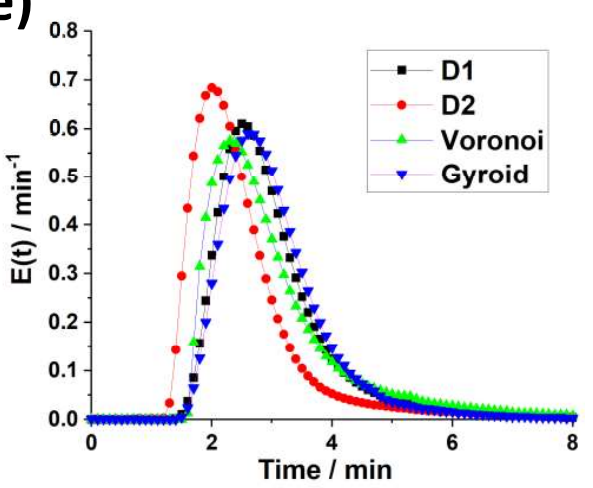

b)

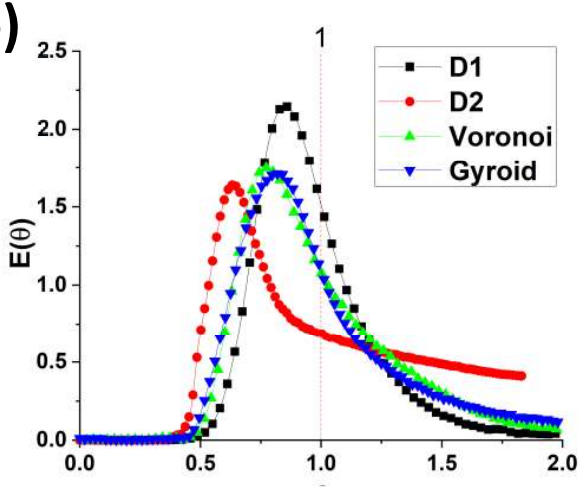

d)

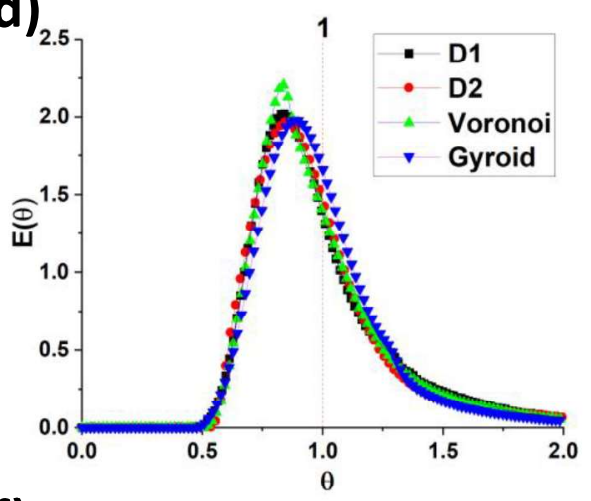

f)

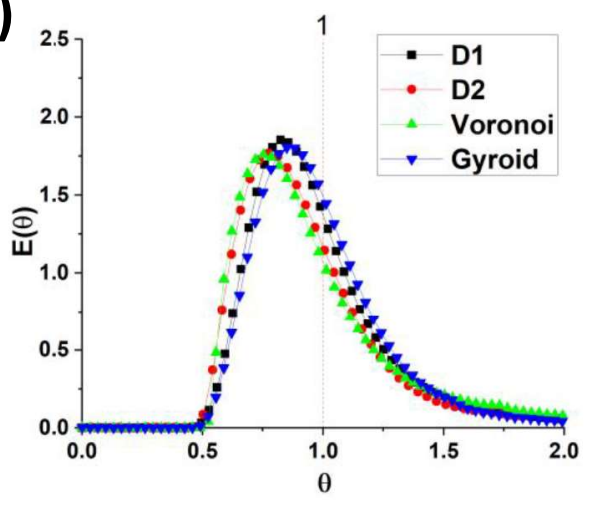

3

\section{Figure 6: Comparison of residence time distribution of the monolith designs - a) RTD and b) normalized RTD curves at the liquid} flowrate of $0.1 \mathrm{~mL} \min ^{-1}$; c) RTD and d) normalized RTD curves at the liquid flowrate of $0.5 \mathrm{~mL} \mathrm{~min}^{-1}$; e) RTD and f) normalized RTD curves at the liquid flowrate of $1 \mathrm{~mL} \mathrm{~min}^{-1}$.

In case of the single-phase liquid flow, the pulse response is broad and non-symmetrical, with the presence of tailing. This represents a flow pattern between plug flow and laminar flow at all flowrates $(0.1,0.5$ and

$1 \mathrm{~mL} \mathrm{~min}-1$ ), as shown in Figure 6. As expected, the $\mathbf{D 2}$ design provided the shortest mean residence time 


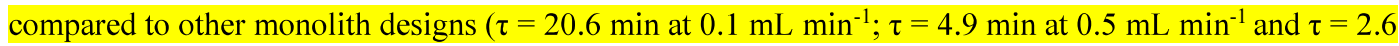

$2 \min$ at $1 \mathrm{~mL} \mathrm{~min}-1$ ), concurrent with $\mathbf{D 2}$ possessing the lowest internal volume of all the monolith structures.

3 The normalised RTD $(\mathrm{E}(\theta)$ ) curves (Figure 6B, 6D \& 6F), which are independent of reactor size, were

4 nearly identical at the flow rate of $0.5 \mathrm{~mL} \mathrm{~min}^{-1}$ for all 4 monolith designs. The $\mathrm{E}(\theta)$ curves show an early

5 peak and the presence of tailing, indicating back mixing due to a parabolic flow profile, which is associated

6 with laminar flow [10,11]. When the flowrate was increased to $1 \mathrm{~mL} \mathrm{~min}^{-1}$, the $\mathbf{D 2}$ and Voronoi designs

7 showed slight deviations as the peak shifted to the left of the mean residence time $(\theta=1)$, and exhibiting

8 an increase in the spread of the curve, highlighted by an increase in $\sigma_{\theta}^{2}$ (ESI, Table S4). At the flow rate of

$90.1 \mathrm{~mL} \mathrm{~min}{ }^{-1}$, D2 significantly shifts away from $\theta=1$, indicating a significant increase in stagnant regions

$10[11,12]$.

11 Performing the same analysis with a biphasic flow of gas and liquid provided similar results; all monolith

12 designs provided near identical normalised RTD profiles (Figure 7). Compared to single-phase flow, the

13 maximum $\mathrm{E}(\theta)$ values were shifted to slightly lower $\theta$ values in the biphasic flow system and the form of

14 the RTD profiles had changed. This indicates presence of bypassing and dead zones, which reduces the

15 effective reactor volume, so the active reactor volume (available for liquid phase flow) is smaller than

16 expected [13].
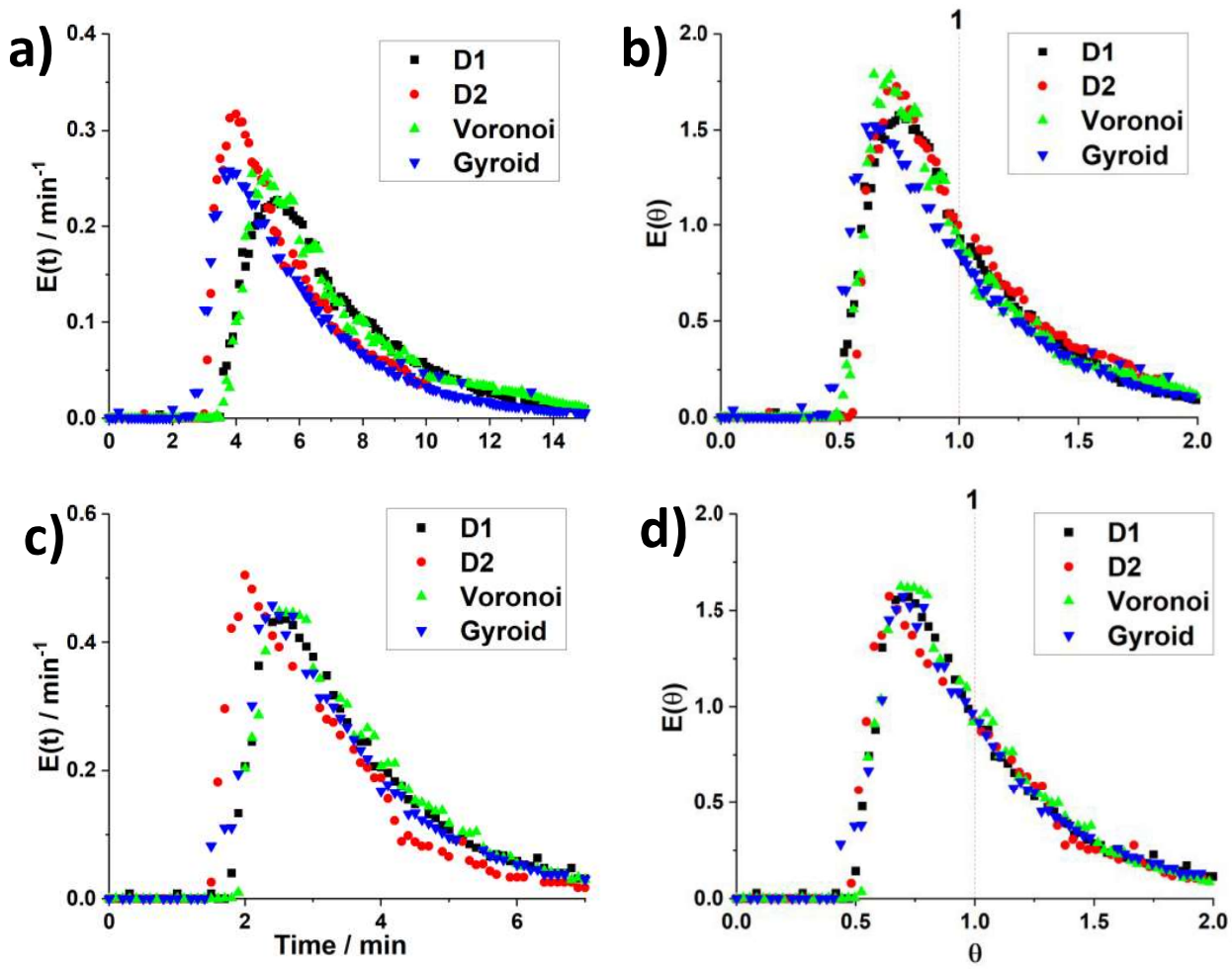
Figure 7: Comparison of residence time distribution of the monolith designs - a) RTD and b) normalized RTD curves at the liquid flowrate of $0.5 \mathrm{~mL} \mathrm{~min}^{-1}$ and gas flowrate of $1.6 \mathrm{~mL} \mathrm{~min}^{-1}$; ) RTD and d) normalized RTD curves at the liquid flowrate of $1 \mathrm{~mL}$ $\mathrm{min}^{-1}$ and gas flowrate of $2.3 \mathrm{~mL} \mathrm{~min}^{-1}$.

4

$5 \quad 3.3$ Singlet oxygen photosensitisation efficiency

6 We proceeded to test the efficiency of the fabricated monoliths for singlet oxygen $\left({ }^{1} \mathrm{O}_{2}\right)$ photosensitisation, 7 using the oxidation of aqueous 2 -furoic acid (1, Scheme 2) as a model reaction to gauge efficiency. The endoperoxide I [16]. This unstable intermediate readily decarboxylates and ring-opens the endoperoxide. mechanism of generating photosensitised singlet oxygen is well studied and proceeds as illustrated in Scheme $2[2,14,15]$. More detailed discussion of the mechanism can be found in the ESI (Section S8). Unlike other reactive oxygen species, ${ }^{1} \mathrm{O}_{2}$ is a singlet diradical which imparts much greater chemoselectivity for $(2 \mathrm{n}) \pi$ systems, such as alkenes, dienes and heteroatoms. For 5-membered aromatic heterocycle substrates, such as $\mathbf{1}$, singlet oxygen reacts exclusively via an Alder-ene [4+2] cycloaddition to give the The subsequent protonation yields the $\gamma$-lactone product, 5-hydroxy-5H-furan-2-one 2 [2,17].
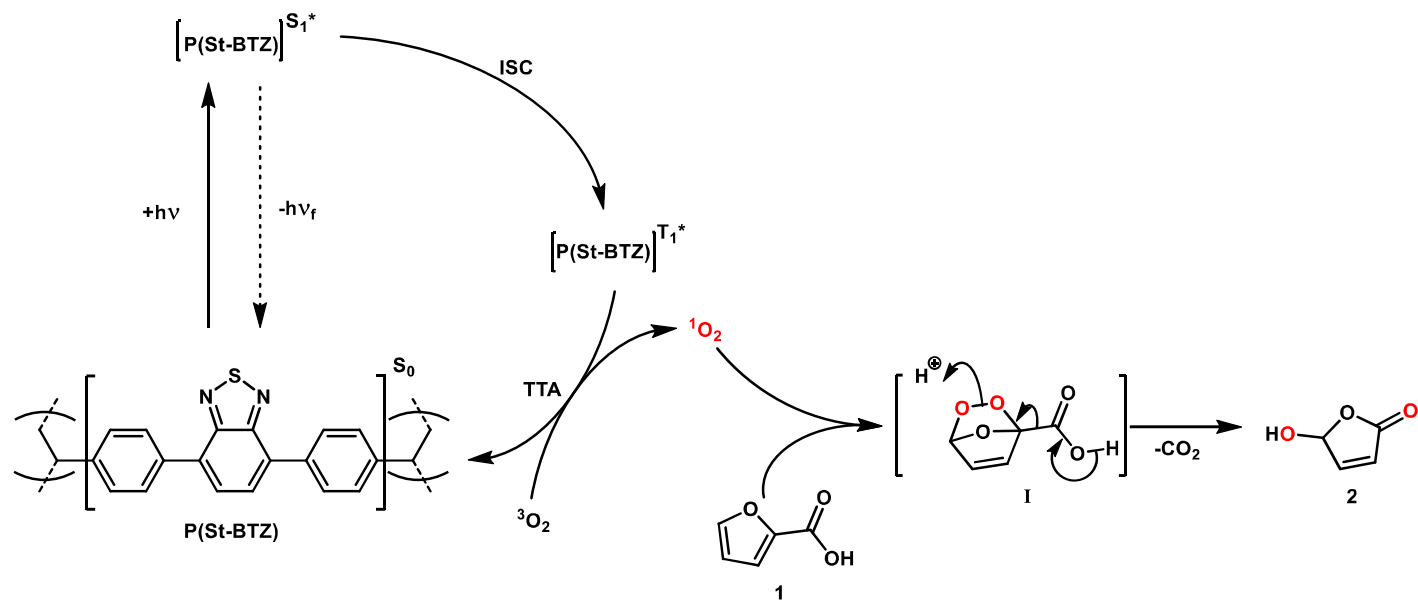

Scheme 2: Mechanism of singlet oxygen photosensitisation by P(St-BTZ) and subsequent oxidation of 2-furoic acid $\mathbf{1}$ to $\gamma$-lactone, 5-hydroxy-5H-furan-2-one $\mathbf{2}$. $+\mathbf{h v}=$ photon absorption, $-\mathbf{h} \mathbf{v}_{\mathbf{f}}=$ fluorescence photon emission, $\mathbf{I S C}=$ intersystem crossing, TTA $=$ triplet-triplet annihilation.

The lifetime of ${ }^{1} \mathrm{O}_{2}$ is highly dependent on solvent and temperature due to electronic-to-vibrational energy transfer facilitating non-radiative decay back to the ${ }^{3} \mathrm{O}_{2}$ ground state $[18,19]$. Counterintuitively, we elected to use water as the solvent in our system which provides the lowest singlet oxygen lifetime of all common laboratory solvents $(3.1 \mu \mathrm{s})$ [20]. This was for a few reasons: (i) water is considered a green solvent, (ii) substrate 1, product $\mathbf{2}$ and ${ }^{3} \mathrm{O}_{2}$ have good solubility in water, (iii) the monolith polymer materials are 
1 relatively hydrophobic, such that water will not cause the monoliths to swell and distort the structures, (iv)

2 photosensitised singlet oxygen is a promising candidate for environmental remediation of waste water [21-

3 23].

4 We screened the performance of the four monolith designs at three flowrates with a total cycling time of 3

5 hours. The results are presented in the ESI (Table S6), and a comparison of total conversion over 3 hours

6 and space-time yields vs. flow rate for each design is presented in Figure 8.

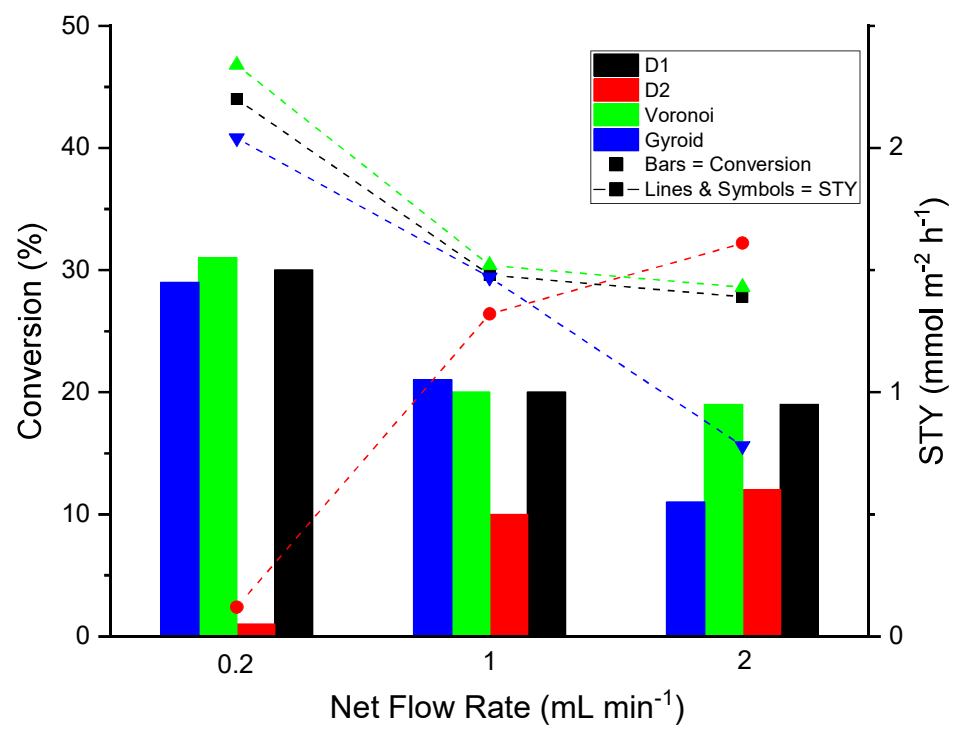

Figure 8: Influence of the flowrate on the 2-furoic acid conversion in 3D printed monoliths and the space-time yield (STY). Reactions were cycled in a continuous loop through the reactor for a total of 3 hours. The net flow rate is the combined flow rate of the gas and solution phases from their respective pump. In all cases, the flow rate of gas and solution were equivalent.

All designs were capable of photosensitising singlet oxygen and subsequently producing 2. As was anticipated, the D2 monolith provided the lowest conversion and STY across all three flowrates, except for $1 \mathrm{~mL} / \mathrm{min}$ at which $\mathbf{D 2}$ surpassed the Gyroid designs conversion by $1 \%$, which is within the error of the ${ }^{1} \mathrm{H}$ NMR analysis. D1 and Voronoi proved to be the optimal designs as they maintained the highest conversion across all flow rates. As the experiments were performed with continuous recycling of the same reaction mixture, the total residence time and light exposure is constant for all flow rates and designs (180 minutes). Hence, we can assume that the difference in productivity between designs is entirely dependent upon the surface area, fluid dynamics and the efficiency of photon transport through the structures. D1, Voronoi and Gyroid achieved the highest conversions and STYs at the lowest net-flow rate tested. This was counterintuitive as usually static mixing elements will display better mass transport and increased gas-liquid 
1 interfacial area at higher flow rates [24]. We propose as the total irradiance time for each flow rate is 2 constant, the lower flow rate is providing the best fluid dynamics and distribution of the gas and liquid

3 phases, leading to the enhanced productivity.

4 D2 followed the trend expected for a static mixing element, however the magnitude of the enhancement 5 between 0.2 and $1 \mathrm{~mL} / \mathrm{min}$ was surprising. In fact, at the fastest net-flow rate of $2 \mathrm{~mL} / \mathrm{min}$, D2 had a higher 6 space-time yield than the more intricate designs at either 1 or $2 \mathrm{~mL} / \mathrm{min}$. Rationalising this was not 7 immediately obvious, however, Billet and co-workers reported that traditional 'honeycomb' monoliths 8 display maldistributed gas-liquid phase distribution, depending on flowrate [25]. At low flow rates, the 9 distribution of the liquid phase is concentrated to the center channels, and at higher flowrates the distribution 10 is more uniform. We believe that this same effect is occurring within the D2 monolith design as this forms 11 a logical rationale for our experimental observations: The channels of the $\mathbf{D 2}$ design were contained within 12 a cylinder such that photons had to pass through a solid layer of P(St-BTZ) material to activate the channel 13 surfaces. As can be seen in Figure 5, the wall thickness between the outer channels and the monolith exterior 14 are relatively thin and transparent, whereas the internal channels are completely masked by the outer layers, 15 and likely receive very little irradiance. The RTD analysis of the D2 monolith for the monophasic liquid 16 flow at $0.1 \mathrm{~mL} \mathrm{~min}^{-1}$ was suggestive of this effect, unfortunately the biphasic RTD profile could not be 17 obtained at such low flow rates due to the long residence time of gas slugs in the spectrometer. We instead 18 fabricated the D2 monolith using the native clear resin and repeated the RTD analysis without the 19 spectrometer, in an attempt to visualize the maldistribution as the tracer passed through the immobilized monolith. Gratifyingly, this effect was easily observed and captured with a camera (see ESI, Figure S3).

21 The tracer could be clearly seen passing through a single channel of the monolith as primarily a single phase, whilst other channels remained relatively stagnant. This confirmed our speculation of maldistribution and supports our rationalization of the photosensitization efficiency of the D2 monolith at varied flow rates. In all cases, the efficiency of these reactors was significantly greater than the flow reactor published in our previous study, which obtained 5\% conversion of $\mathbf{1}$ to $\mathbf{2}$ in 5 hours, under near identical conditions [6].

\section{Conclusions}


1 This study has demonstrated stereolithographic additive manufacturing as a methodology for the rapid

2 prototyping of flow reactor components. Functional materials were produced in situ through addition of a photocatalytic monomer to a commercial resin, enabling fabrication of heterogeneous photocatalysts. Despite the St-BTZ monomer having significant spectral overlap with the DLP printers' light emission, stable monolithic structures with photocatalytic ability were successfully fabricated through printing parameter optimisation. Successful incorporation of St-BTZ was confirmed by solid-state UV-Vis. spectroscopy and allowed the determination of $0.19 \mathrm{wt} . \%$ as an optimal loading to balance solubility, light attenuation and accelerated polymerisation kinetics within the resin. All fabricated monolith designs were capable of producing photosensitised singlet oxygen in continuous flow which was proven through the conversion of 2-furoic acid 1 to the $\gamma$-lactone, 5-hydroxy-5H-furan-2-one 2. The effects of monolith structure and flow rate were investigated with surprising results, finding that the simplest design, D2, provided the highest space-time at high flowrates. We propose that maldistribution of the flowing gas and liquid phases was the productivity limiting factor in these designs, rather than mass transfer at the monolith surface. This study demonstrates AMs ability to rapidly fabricate reactor prototypes that are neither commercially available, nor easily produced through conventional manufacturing methods. This is a promising technology for the development of bespoke, multi-functional, flow reactor components for continuous production of fine chemicals through heterogeneous photocatalysis, with enhanced sustainability as the product purification requirements are reduced and the catalyst is easily recycled $[2,26,27]$. Furthermore, the development of easily manufactured and efficient heterogeneous photosensitisers for the generation of singlet oxygen in aqueous media is an auspicious move towards methodology $[2,23,28-30]$.

The authors declare that they have no known competing financial interests or personal relationships that could have appeared to influence the work reported in this paper.

\section{Conflict of interests}


2 The research work is supported by UK Engineering and Physical Science Research Council EPSRC Grants

3 (EP/R012164/2 and EP/S000933/1) and Royal Society Research Grant (RSG\R1\180162) We also

4 acknowledge Vapourtec Ltd. for their invaluable technical support. We would like to thank the Engineering and Physical Sciences Research Council, Heriot-Watt University and the CRITICAT Centre for Doctoral

\section{References}

[1] A.J. Capel, R.P. Rimington, M.P. Lewis, S.D.R. Christie, 3D printing for chemical, pharmaceutical and biological applications, Nat. Rev. Chem. 2 (2018) 422-436. doi:10.1038/s41570-018-0058-y.

[2] C.G. Thomson, A.-L. Lee, F. Vilela, Heterogeneous photocatalysis in flow chemical reactors, Beilstein J. Org. Chem. 16 (2020) 1495-1549. doi:10.3762/bjoc.16.125.

[3] J. Azuaje, C.R. Tubío, L. Escalante, M. Gómez, F. Guitián, A. Coelho, O. Caamaño, A. Gil, E. Sotelo, An efficient and recyclable 3D printed $\alpha$-Al 2 O 3 catalyst for the multicomponent assembly of bioactive heterocycles, Appl. Catal. A Gen. $530 \quad$ (2017) 203-210. doi:10.1016/j.apcata.2016.11.031.

[4] P.J. Kitson, M.D. Symes, V. Dragone, L. Cronin, Combining 3D printing and liquid handling to produce user-friendly reactionware for chemical synthesis and purification, Chem. Sci. 4 (2013) 3099-3103. doi:10.1039/c3sc51253c.

[5] Formlabs Inc., FDM vs. SLA: Compare the Two Most Popular Types of 3D Printers, (n.d.). https:/formlabs.com/uk/blog/fdm-vs-sla-compare-types-of-3d-printers/\#Materials and Applications (accessed July 31, 2020).

[6] A. Zhakeyev, J. Tobin, H. Wang, F. Vilela, J. Xuan, Additive manufacturing of photoactive polymers for visible light harvesting, Energy Procedia. 158 (2019) 5608-5614. doi:10.1016/j.egypro.2019.01.579. 
species on the kinetics of free radical photopolymerization, Polym. Chem. 4 (2013) 2475-2479. doi:10.1039/C3PY21163K

[8] R. Shenoy, C.N. Bowman, Mechanism and Implementation of Oxygen Inhibition Suppression in Photopolymerizations by Competitive Photoactivation of a Singlet Oxygen Sensitizer, Macromolecules. 43 (2010) 7964-7970. doi:10.1021/ma1012682.

[9] J.M. Tobin, T.J.D. McCabe, A.W. Prentice, S. Holzer, G.O. Lloyd, M.J. Paterson, V. Arrighi, P.A.G. Cormack, F. Vilela, Polymer-Supported Photosensitizers for Oxidative Organic Transformations in Flow and under Visible Light Irradiation, ACS Catal. 7 (2017) 4602-4612. doi:10.1021/acscatal.7b00888.

[10] O. Okafor, A. Weilhard, J.A. Fernandes, E. Karjalainen, R. Goodridge, V. Sans, Advanced reactor engineering with 3D printing for the continuous-flow synthesis of silver nanoparticles, React. Chem. Eng. 2 (2017) 129-136. doi:10.1039/c6re00210b.

[11] O. Levenspiel, Chemical Reaction Engineering, 3rd ed., Wiley, 1999.

[12] M.T. Kreutzer, J.J.W. Bakker, F. Kapteijn, J.A. Moulijn, P.J.T. Verheijen, Scaling-up multiphase monolith reactors: Linking residence time distribution and feed maldistribution, Ind. Eng. Chem. Res. 44 (2005) 4898-4913. doi:10.1021/ie0492350.

[13] H. Fogler, Elements of Chemical Reaction Engineering, 4th ed., Prentice Hall, 2005.

[14] C.G. Thomson, C.M.S. Jones, G. Rosair, D. Ellis, J. Marques-Hueso, A.L. Lee, F. Vilela, Continuous-flow synthesis and application of polymer-supported BODIPY Photosensitisers for the generation of singlet oxygen; process optimised by in-line NMR spectroscopy, J. Flow Chem. 10 (2020) 327-345. doi:10.1007/s41981-019-00067-4.

[15] M.C. DeRosa, R.J. Crutchley, Photosensitized singlet oxygen and its applications, Coord. Chem. Rev. 233-234 (2002) 351-371. doi:10.1016/S0010-8545(02)00034-6.

[16] A.G. Griesbeck, A. de Kiff, J.M. Neudoerfl, S. Sillner, Singlet oxygen addition to cyclo-1,3hexadienes from natural sources and from organocatalytic enal dimerization, Arkivoc. 2015 (2015) 101. doi:10.3998/ark.5550190.p008.994.

[17] J.A. Navio, J. Fuentes Mota, M.A. Pradera Adrian, M. Garcia Gomez, Oxidation of 2-furoic acid 
via singlet oxygen generated photochemically, J. Photochem. Photobiol. A Chem. 52 (1990) 9195. doi:10.1016/1010-6030(90)87094-R.

[18] J.R. Hurst, J.D. McDonald, G.B. Schuster, Lifetime of Singlet Oxygen in Solution Directly Determined by Laser Spectroscopy, J. Am. Chem. Soc. 104 (1982) 2065-2067. doi:10.1021/ja00371a065.

[19] M. Bregnhøj, M. Westberg, F. Jensen, P.R. Ogilby, Solvent-dependent singlet oxygen lifetimes: temperature effects implicate tunneling and charge-transfer interactions, Phys. Chem. Chem. Phys. 18 (2016) 22946-22961. doi:10.1039/C6CP01635A.

[20] C. Schweitzer, R. Schmidt, Physical Mechanisms of Generation and Deactivation of Singlet Oxygen, Chem. Rev. 103 (2003) 1685-1758. doi:10.1021/cr010371d.

[21] J. Shen, R. Steinbach, J.M. Tobin, M. Mouro Nakata, M. Bower, M.R.S. McCoustra, H. Bridle, V. Arrighi, F. Vilela, Photoactive and metal-free polyamide-based polymers for water and wastewater treatment under visible light irradiation, Appl. Catal. B Environ. 193 (2016) 226-233. doi:10.1016/j.apcatb.2016.04.015.

[22] M. Thandu, C. Comuzzi, D. Goi, Phototreatment of water by organic photosensitizers and comparison with inorganic semiconductors, Int. J. Photoenergy. 2015 (2015) 10-12. doi:10.1155/2015/521367.

[23] D. García-Fresnadillo, Singlet Oxygen Photosensitizing Materials for Point-of-Use Water Disinfection with Solar Reactors, ChemPhotoChem. 2 (2018) 512-534. doi:10.1002/cptc.201800062.

[24] A. Heyouni, M. Roustan, Z. Do-Quang, Hydrodynamics and mass transfer in gas-liquid flow through static mixers, Chem. Eng. Sci. 57 (2002) 3325-3333. doi:10.1016/S0009-2509(02)002026.

[25] A. Devatine, H. Chaumat, S. Guillaume, B. Tati Tchibouanga, F. Durán Martínez, C. Julcour, A.M. Billet, Hydrodynamic study of a monolith-type reactor for intensification of gas-liquid applications, Chem. Eng. Process. Process Intensif. $122 \quad$ (2017) 277-287. doi:https://doi.org/10.1016/j.cep.2017.10.015. 
1 [26] A.O. Ibhadon, P. Fitzpatrick, Heterogeneous Photocatalysis: Recent Advances and Applications, Catalysts. 3 (2013) 189-218. doi:10.3390/catal3010189.

[27] Y. Cai, Y. Tang, L. Fan, Q. Lefebvre, H. Hou, M. Rueping, Heterogeneous Visible-Light Photoredox Catalysis with Graphitic Carbon Nitride for $\alpha$-Aminoalkyl Radical Additions, Allylations, and Heteroarylations, ACS Catal. 8 (2018) 9471-9476. doi:10.1021/acscatal.8b02937.

[28] M. Pelaez, N.T. Nolan, S.C. Pillai, M.K. Seery, P. Falaras, A.G. Kontos, P.S.M. Dunlop, J.W.J. Hamilton, J.A. Byrne, K. O'Shea, M.H. Entezari, D.D. Dionysiou, A review on the visible light active titanium dioxide photocatalysts for environmental applications, Appl. Catal. B Environ. 125 (2012) 331-349. doi:10.1016/j.apcatb.2012.05.036.

[29] V. Homem, L. Santos, Degradation and removal methods of antibiotics from aqueous matrices - A review, J. Environ. Manage. 92 (2011) 2304-2347. doi:10.1016/j.jenvman.2011.05.023.

[30] D. Cambié, C. Bottecchia, N.J.W. Straathof, V. Hessel, T. Noël, Applications of Continuous-Flow Photochemistry in Organic Synthesis, Material Science, and Water Treatment, Chem. Rev. 116 (2016) 10276-10341. doi:10.1021/acs.chemrev.5b00707. 
SLA additive manufacturing:

- Freedom of Design

- Rapid prototyping

- High resolution

- Facile incorporation of catalyst
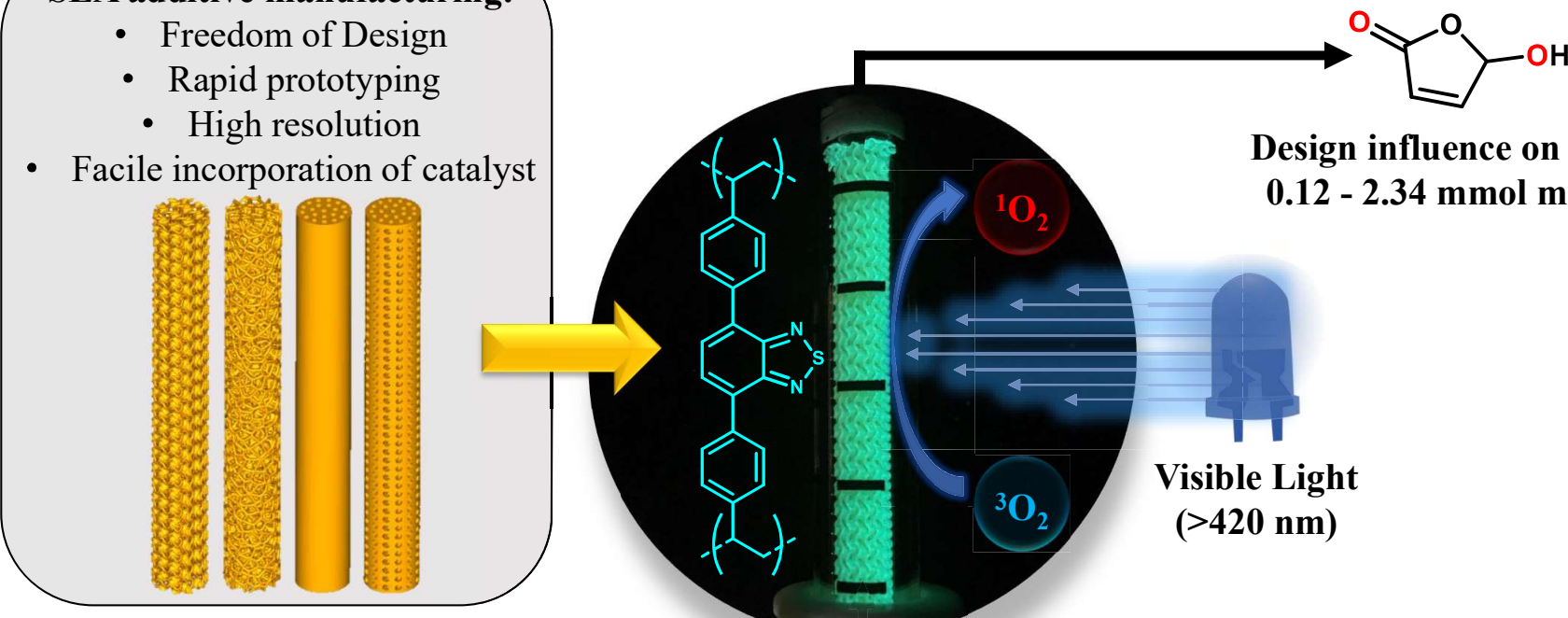

Design influence on STY:

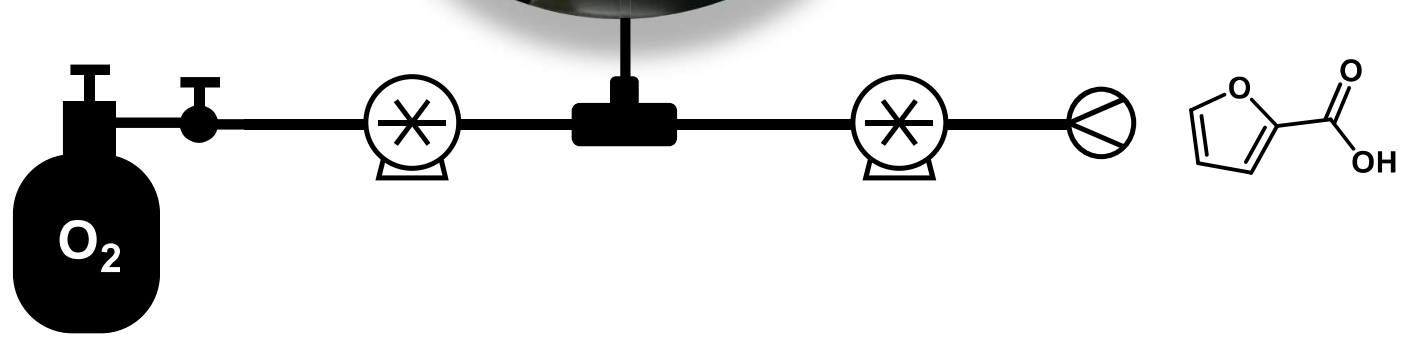

Visible Light

$(>420 \mathrm{~nm})$

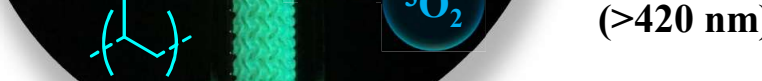


(A) Previous Work: Photocatalytic Flow Reactor

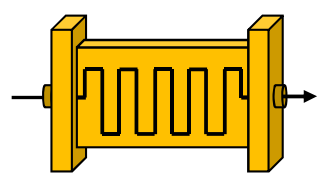

Photocatalyst in external surfaces block light from active sites in flow channels

Simple 2D design; could be manufactured conventionally
(B) This Work: Photocatalytic Monoliths
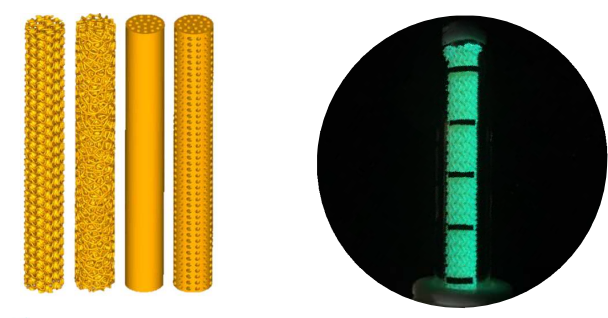

Active surfaces irradiated directly $\checkmark$ Improved gas-liquid reactivity $\checkmark \begin{aligned} & \text { Non-Commercially available, nor easily } \\ & \text { manufactured through conventional } \\ & \text { methods }\end{aligned}$

Figure 1: Comparison of disadvantages of previously reported SLA manufacture of flow reactors and advantages of the SLA manufactured functional monoliths presented in this work. 


\subsection{9}

$\downarrow$

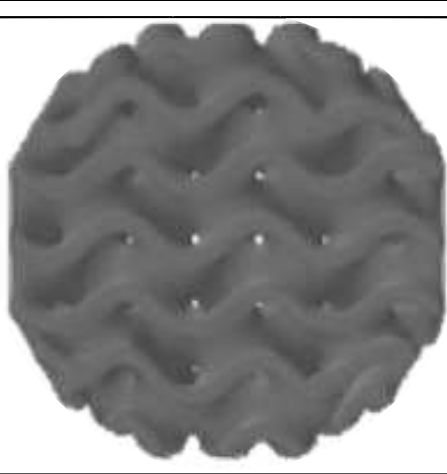

L

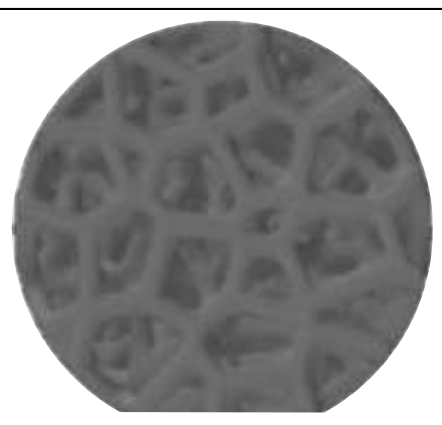

$w \uparrow$

L

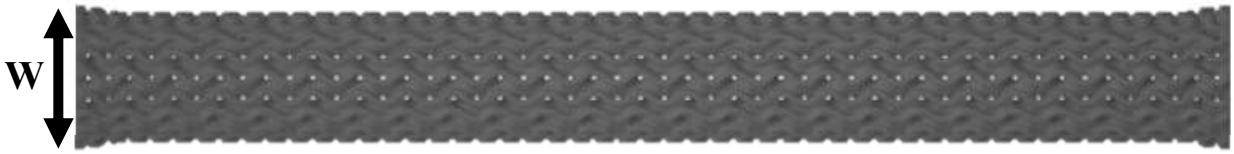
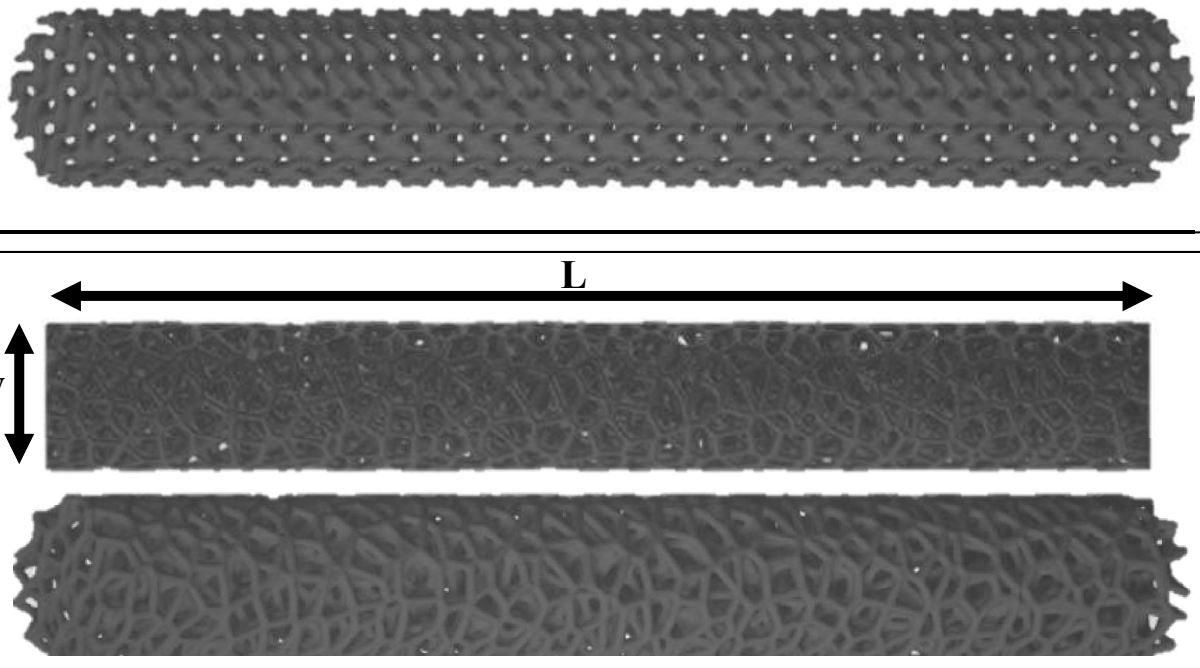


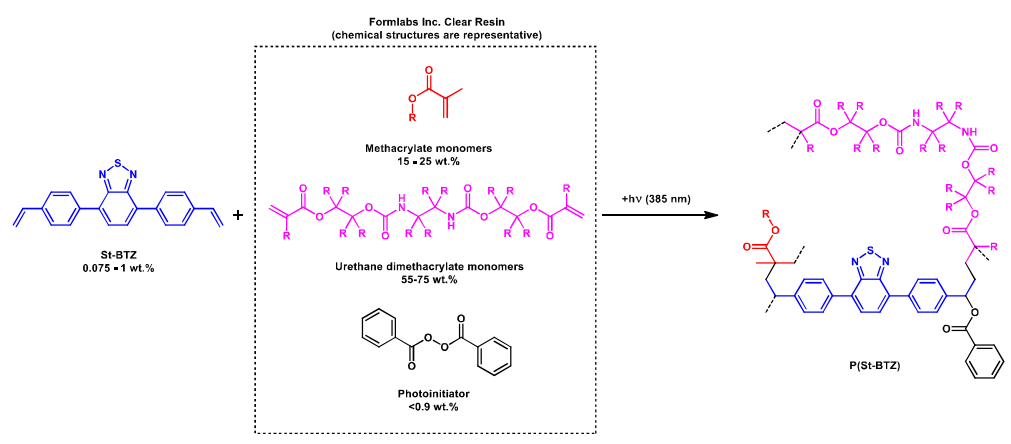

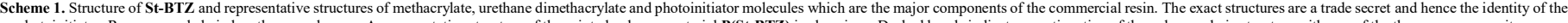
photoinitiator, R-groups and chain lengths are unknown. A representative structure of the printed polymer material P(St-BTZ) is also given. Dashed bonds indicate a continuation of the polymer chain structure with any of the three monomer units, or a terminal capped with photoinitiator, in proportions respective of the resin composition. 

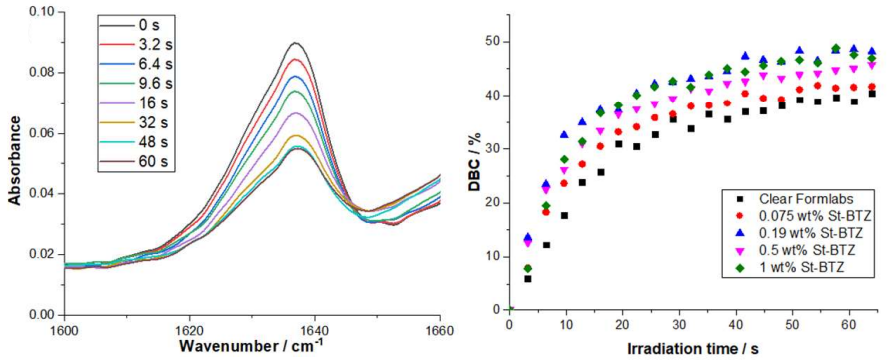

Figure 3: A) Real-time FTIR spectra of Formlabs Clear resin with 0 wt.\% St-BTZ. B) DBC (\%) vs. time trace for various St-BTZ wt.\% loading. 

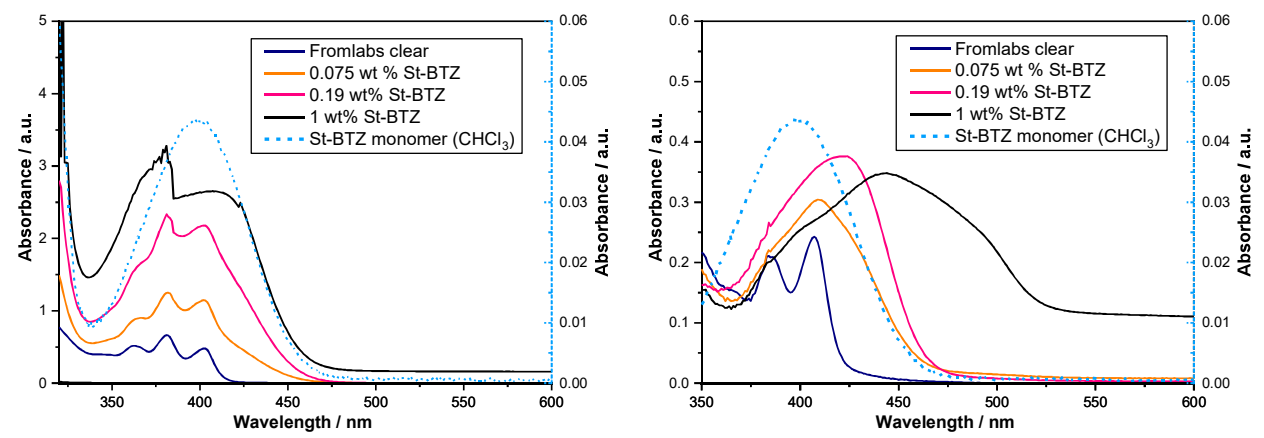

Figure 4: UV/vis absorption spectra of (A) Formlabs Clear resin with different St-BTZ concentrations (IPA) and (B) Solid-state UV-Vis. absorption spectra of 3D printed films with various St-BTZ concentration. The solution-state absorption spectrum of the St-BTZ monomer $\left(\mathrm{CHCl}_{3}\right)$ is shown as a dashed, light-blue line in both graphs for reference, with the $\mathrm{Y}$-axis shown on the right. 


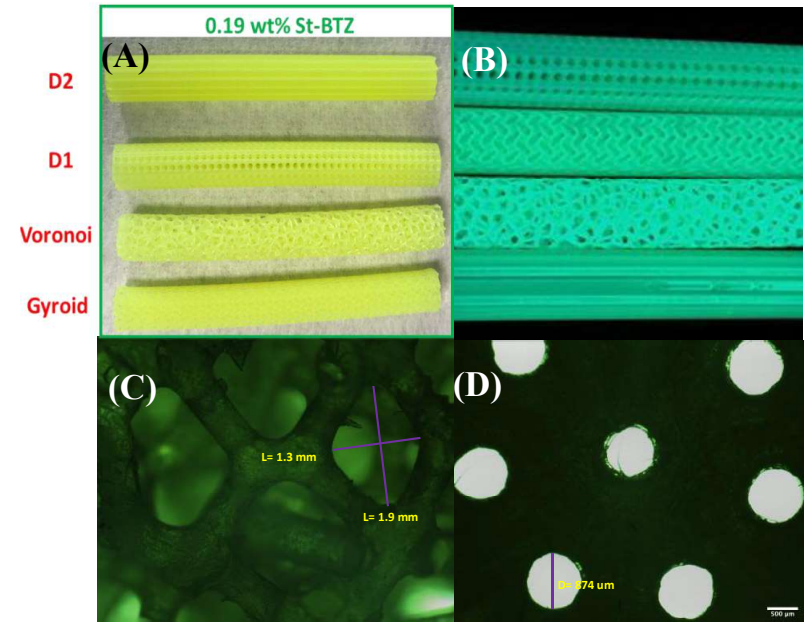

Figure 5: (A) 3D printed and cured photo-active monoliths with $0.19 \mathrm{wt} \% \mathrm{St}-\mathrm{BTZ}$ concentration. (B) Image of the monoliths under long-wave UV irradiation, showing the blue glow of the incorporated St-BTZ monomers (from top to bottom: D1, Gyroid, Voronoi, D2). (C) Microscope image of the Voroni monolith with length (L) of a diamond shaped void given for reference. (D) Microscope image of a cross section of the D2 monolith with channel diameter (D) given for reference. 

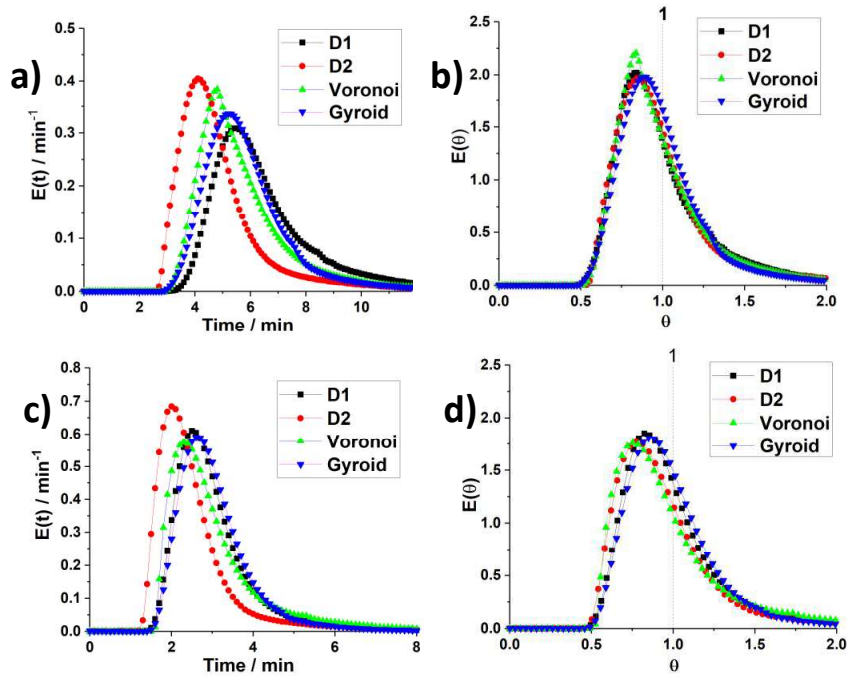

Figure 6: Comparison of residence time distribution of the monolith designs - a) RTD and b) normalized RTD curves at the liquid flowrate of $0.5 \mathrm{~mL} \mathrm{~min}^{-1}$; c) RTD and d) normalized RTD curves at the liquid flowrate of $1 \mathrm{~mL} \mathrm{~min}^{-1}$. 

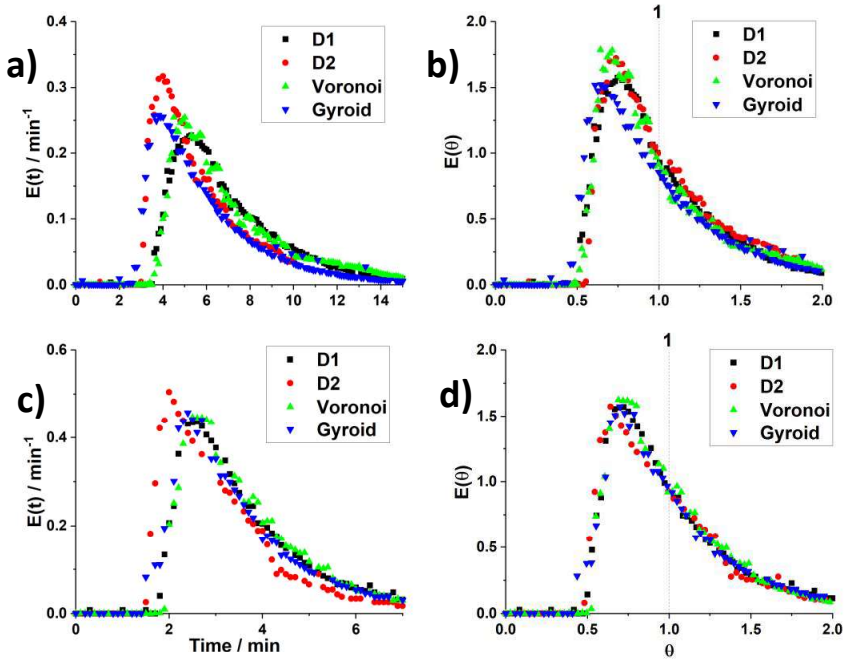

Figure 7: Comparison of residence time distribution of the monolith designs - a) RTD and b) normalized RTD curves at the liquid flowrate of $0.5 \mathrm{~mL} \mathrm{~min}^{-1}$ and gas flowrate of $1.6 \mathrm{~mL} \mathrm{~min}^{-1}$; c) RTD and d) normalized RTD curves at the liquid flowrate of $1 \mathrm{~mL} \mathrm{~min}^{-1}$ and gas flowrate of 2.3 $\mathrm{mL} \min ^{-1}$. 


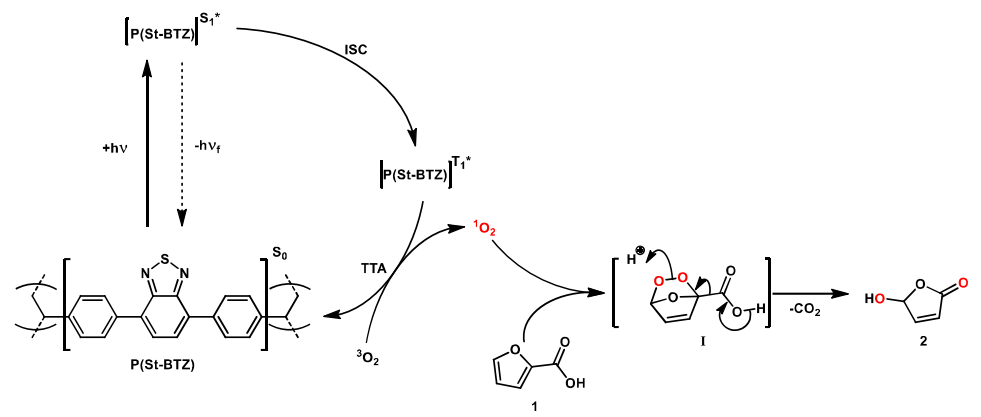

Scheme 2: Mechanism of singlet oxygen photosensitisation by $\mathbf{P}(\mathbf{S t}-\mathbf{B T Z})$ and subsequent oxidation of 2-furoic acid 1 to $\gamma$-lactone, 5 -hydroxy$5 \mathrm{H}$-furan-2-one $\mathbf{2}$. $\mathbf{t h v}=$ photon absorption, $-\mathbf{- h} \mathbf{v}_{\mathrm{f}}=$ fluorescence photon emission, ISC $=$ intersystem crossing, TTA = triplet-triplet annihilation. 


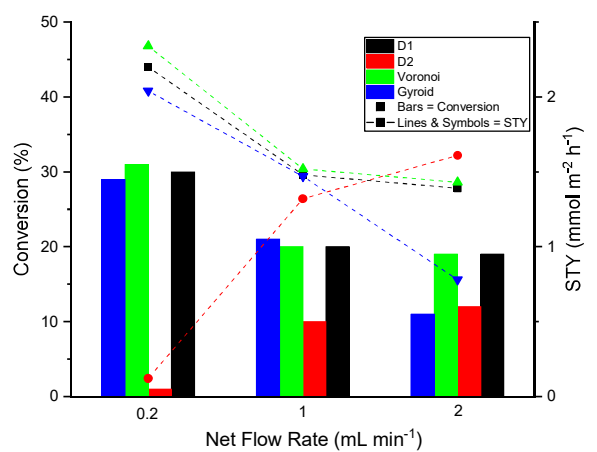

Figure 4: Influence of the flowrate on the 2-furoic acid conversion in 3D printed monoliths and the space-time yield (STY). Reactions were cycled in a continuous loop through the reactor for a total of 3 hours. 

manuscript:

\section{Additive manufacturing of intricate and inherently}

\section{photocatalytic flow reactor components}

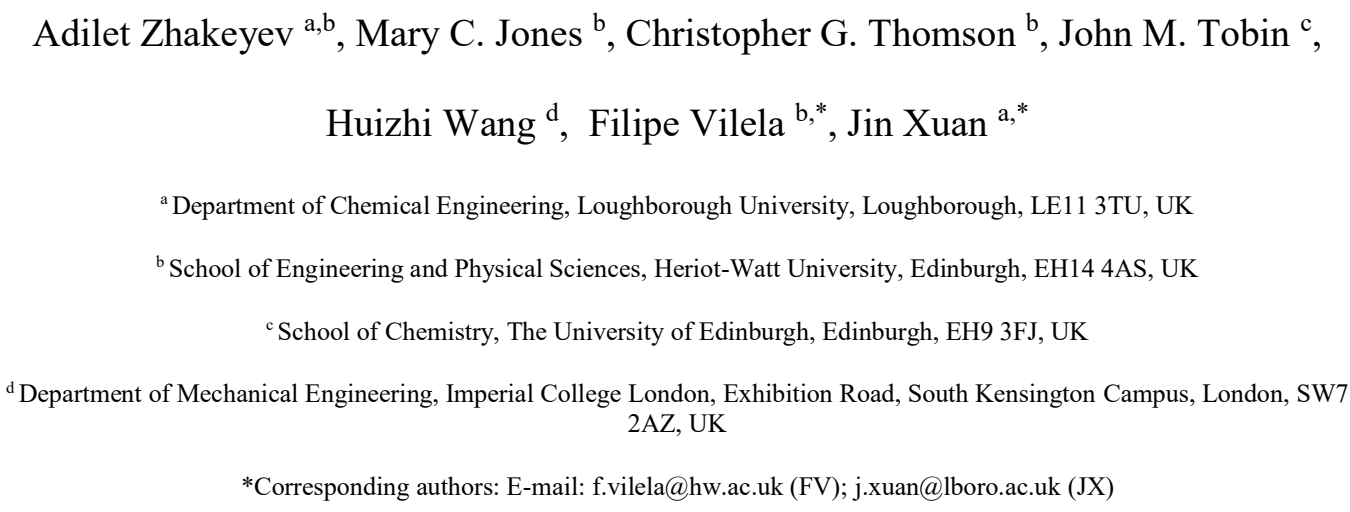

Adilet Zhakeyev: 3D printing, Validation, Formal Analysis, Writing- Reviewing and Editing. Mary C. Jones: Photosensitisation experiments in flow, Validation, Formal Analysis, Writing- Reviewing and Editing. Christopher G. Thomson: Analysis, Writing- Original draft preparation, Writing- Reviewing and Editing. John M. Tobin: Synthesis of the photoactive monomer. Huizhi Wang: Software, Validation. Filipe Vilela: Conceptualization, Writing- Reviewing and Editing, Supervision, Funding acquisition, Project administration. Jin Xuan: Conceptualization, Writing- Reviewing and Editing, Supervision, Funding acquisition, Project administration. 